\title{
Effect of electric discharge machining of die steel DIN 1.2714 and DIN 1.2343 on surface characteristics and performance measures
}

\author{
M. A. Majid ${ }^{1} \&$ A. M. Issa ${ }^{2}$ \\ ${ }^{1}$ Department of Production Engineering and Metallurgy, \\ University of Technology, Iraq \\ ${ }^{2}$ Department of Mechanical Engineering, Al Zawia University, Libya
}

\begin{abstract}
Electrical Discharge Machining (EDM) is progressively becoming a vital tool in modern industry. Its performance, success and outcome depend upon the selection of suitable electrical and non-electrical parameters. In the present research EDM was applied to die steels DIN 1.2714 and powder mixed electrical discharge machining (PMEDM) was applied to die steels DIN 1.2714 and DIN 1.2343. Regarding surface characteristics, surface roughness is found to increase with current increase and white layer thickness (WLT) increased too. Similarly, the effect of increasing pulse duration on surface roughness and white layer thickness is found to be comparable. As for performance measures, steel DIN 1.2714 results have indicated reduced ratio of Metal Removal Rate (MRR) to Electrode Wear Rate (EWR) from about 60 to 8.5 upon current increase. On the other hand, the ratio (MRR/EWR) exhibited significant increase upon increasing pulse duration, attributed mainly to reduced EWR. Results due to EDM using graphite powder in dielectric kerosene, showed reduced electrode consumption. Results to steel DIN 1.2714 indicated a noticeable increase of the ratio (MRR/EWR) at high pulse duration upon increasing powder concentration from 0 to $5.5(\mathrm{~g} / \mathrm{l})$. Statistical analyses showed a significant effect of pulse duration, powder concentration and their interaction on the ratio (MRR/EWR).

Keywords: electric discharge machining, surface roughness, white layer thickness, metal remove rate, electrode wear rate, current and pulse duration.
\end{abstract}




\section{Introduction}

\subsection{Electric discharge machining to meet manufacturing challenges}

Today's manufacturing industry is facing challenges from advanced difficult-tomachine materials, stringent design requirements such as high surface quality and machining costs. The recent developments in the field of EDM have progressed due to the growing application of EDM process and the challenges being faced by the modern manufacturing industries, from the development of new materials. Many of these materials also find applications in other industries owing to their high strength to weight ratio, hardness and heat resisting qualities.

\subsection{Literature review and the need for further research}

EDM has also made its presence felt in new fields such as sports, medical and surgical instruments, optical, dental and jewellery industries, including automotive $R \& D$ areas $[1,2]$. In addition to the advanced materials, stringent design requirements also pose major problems in manufacturing industry. More and more complex shapes (such as an aerofoil section of a turbine blade, complex cavities in dies and molds, non-circular, small, and curved holes), low rigidity structure, and micromechanical components with tight tolerances and fine surface quality are often needed $[1,3]$. Research work in the area of EDM is versatile and the literature has dealt with several issues. Guu et al. [4] investigating EDM of AISI D2 tool steel, showed that recast layer becomes thicker with increased current and pulse duration with an excellent machined surface finish at low pulse energy through reduced occurrence of dielectric fluid bursts and melt expulsions. Lee and Tai [5] findings on tool steels AISI (D2) and (H13) demonstrated increased MRR in agreement with Shankar et al. [2] findings regarding hardened tool steel. Research by many authors [6-12] on different steels using $(\mathrm{Si}, \mathrm{Al}, \mathrm{Ni})$ powder suspension in dielectric produced better surface roughness, with enhanced MRR sometimes. Kansal et al. [13] in a (PMEDM) research on die steel, using graphite powder suspended in dielectric, found that peak current is more prominent than other machining parameters, resulting in about $74 \%$ improvement of metal removal rate (MRR) while contribution of pulse duration was only $5 \%$ and that due to graphite powder concentration was less than $1.0 \%$. Results of research by Wang et al. [14] showed that increasing electrode down time up to $1 \mathrm{sec}$ resulted in increased discharge frequency from 2500 to about $3900 \mathrm{~Hz}$, while increasing electrode jump speed from 2.5 to $6.67 \mathrm{~mm} / \mathrm{sec}$ resulted in increased discharge frequency from 500 to about $2000 \mathrm{~Hz}$. Results due to Shabgarda and Seyedzavvara [15] showed that WLT tripled when pulse duration increased from 12.8 to 100 microsec. However, WLT decreased upon current increase from 7 to $23 \mathrm{~A}$ at relatively high pulse durations $(50$ and $100 \mu \mathrm{s})$, but remains almost unaltered at low pulse duration $(12.8$ and $25 \mu \mathrm{s})$. Flashing efficiency was found to increase with current increase. Due to its significance in modern industry, EDM progress and development is inevitable. Therefore, research in the EDM field has 
increased intensively. The present research studies some electrical and nonelectrical parameters and their influence in EDM of die steels (DIN 1.2714 and DIN 1.2343) and in particular it focuses on the application of graphite power suspension in dielectric fluid to assess the possible benefits that may be attained.

\section{Experimental techniques}

\subsection{Work piece materials equipment and machines}

Tool/die steels DIN1.2714 and DIN1.2343 were selected to produce the work pieces. The chemical composition of those steels is given in Table 1.

Table 1: Chemical composition of the steels.

\begin{tabular}{|l|c|c|c|c|c|c|c|c|c|}
\hline Steel & Element & $\mathrm{C}$ & $\mathrm{Si}$ & $\mathrm{Mn}$ & $\mathrm{Cr}$ & $\mathrm{Mo}$ & $\mathrm{Ni}$ & $\mathrm{V}$ & $\mathrm{Fe}$ \\
\hline DIN 1.2714 & wt \% & 0.55 & 0.30 & 0.75 & 1.10 & 0.50 & 1.70 & 0.10 & Balance \\
\hline DIN 1.2343 & wt \% & 0.39 & 1.10 & 0.40 & 5.20 & 1.20 & - & 0.35 & Balance \\
\hline
\end{tabular}

DIN1.2343 was hardened and tempered to the same hardness level as steel DIN 1.2714. Commercial copper was used to fabricate machining electrodes $20 \mathrm{~mm}$ diameter and $60 \mathrm{~mm}$ length with polished ends. Work specimens dia. $28 \mathrm{~mm}$ and height $15 \mathrm{~mm}$ were prepared for EDM, they were polished to ensure same surface finish of $0.4(\mu \mathrm{m})$. EDM was performed with commercial kerosene as the dielectric fluid, and when performing PMEDM Graphite powder (particle size of $75 \mu \mathrm{m}$ ) was suspended in the dielectric. Charmilles Technologies model (FORM 2-LC) is the electrical discharge machine which was used. Flashing to enhanced circulation was accomplished through a small dielectric circulating system. WLT measured by viewing several fields using an optical microscope type (Olympus GX51). Average surface roughness (Ra) was measured using the device type (Taylor-Hobson Surtronic3+).

\subsection{Investigated variables}

\subsubsection{Electrical discharge machining conditions}

Current effect (I): parameters such as MRR, EWR, Ra, and WLT are all controlled by current applied during machining. The effect of current was studied on 15 specimens of steel DIN1.2714, five levels of current, were employed with positive electrode polarity, $85 \mathrm{~V}$, pulse off time $50 \mu \mathrm{s}$, machining depth $0.3 \mathrm{~mm}$ with dielectric jet flushing at $1 \mathrm{l} / \mathrm{m}$.. Other machining conditions are shown in Table 2. Steel DIN1.2714 was used for this investigation.

Pulse on time effect: MRR, EWR, Ra and WLT are all affected by pulse duration. This was investigated on steel DIN1.2714.

Effect of graphite powder addition on studied parameters: the dielectric is one of the basic elements in EDM process. Powder addition should enhance breakdown of dielectric, it causes gap size increase thus enabling distributing electrical discharges. Graphite powder effect on (MRR/EWR) ratio, Ra, WLT was investigated at four levels of concentrations. Meanwhile, pulse on time at 
three levels was applied. Specimens (36) of each steel were used for this investigation. Table 2 shows EDM conditions employed.

$\mathrm{MRR} / \mathrm{EWR}$ ratio calculations: MRR in $\mathrm{mg} / \mathrm{min}$ and $\mathrm{EWR}$ in $\mathrm{mg} / \mathrm{min}$ were determined from data of work and electrode weight changes during EDM.

Table 2: EDM conditions for current, pulse and graphite powder concentration effect.

\begin{tabular}{|c|c|c|c|}
\hline Operating parameters & \multicolumn{3}{|c|}{ EDM conditions } \\
\hline & Current effect & $\begin{array}{c}\text { Pulse on time } \\
\text { effect }\end{array}$ & Powder conc. effect \\
\hline Work-piece material & Steel DIN 1.2714 & Steel DIN 1.2714 & Both steels \\
\hline Dielectric & Kerosene & Kerosene & Kerosene + Graphite \\
\hline Current amp. & $5.5,8.5,13,17.5,19.5$ & 13 & 13 \\
\hline Voltage volt & 85 & 85 & 85 \\
\hline Pulse on time $\mu$ s & 50 & $25,50,100,200$ & $25,50,100$ \\
\hline Powder concentration $g$ & 1 & 1 & $1,2,4,5.5$ \\
\hline
\end{tabular}

\subsection{Statistical analysis}

T. Test, F- Test, then 2-factor ANOVA Interaction has been applied to test the significance of the obtained results regarding the effect of pulse duration, graphite powder and their interaction on the ratio (MRR/EWR). In addition, pulse duration, steel type and their interaction were also considered.

\section{Results and discussion}

\subsection{Current effect}

Current effect on crater size is shown in Figure 1, it can be seen that higher current leads to larger craters, in effect both metal removal and electrode wear increase, this agrees with previous research findings on others steels.

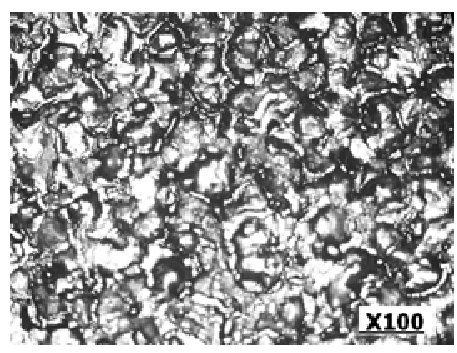

(a)

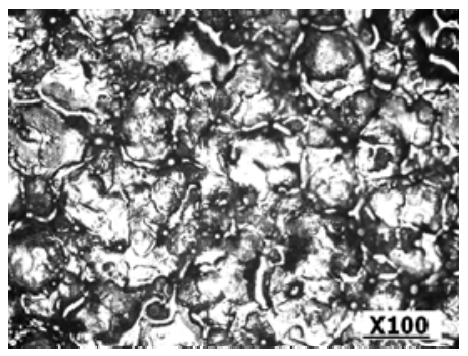

(b)

Figure 1: $\quad$ Optical microphotograph showing EDMed surface of DIN 1.2714 steel specimen, (a) $\mathrm{I}=5.5 \mathrm{~A}$; (b) $\mathrm{I}=13 \mathrm{~A}$. 


\subsubsection{Effect of current on average surface roughness (Ra)}

Average surface roughness measurement results are shown in Figure 2. It is evident that increasing the current causes a corresponding increase in the average surface roughness. Though such increase is limited at low currents; however, significant increase in average surface roughness is exhibited as the current exceeds 13A. This is related directly to the crater size, since at low discharge current spark energy is low leading to the formation of small craters, this is also noted from Figure 1, which includes microphotographs of EDM surfaces due to 5.5 and 13A. This agrees with previous research findings [2, 5].

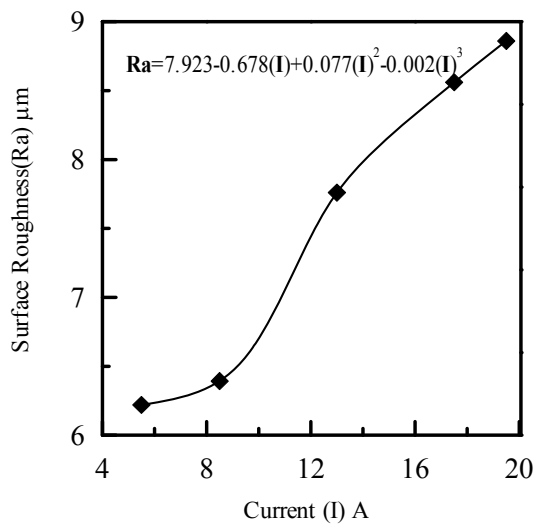

Figure 2: $\quad$ Variation of surface roughness with discharge current of EDM steel DIN 1.2714 specimens, $\mathrm{V}=85 \mathrm{~V}$, Ton=Toff $=50 \mu \mathrm{s}$.

\subsubsection{Effect of current on ratio (MRR/EWR)}

Figure 3, shows the ratio (MRR/EWR) represented versus the current, it can be seen how current increase causes the ratio to decrease sharply from about 61 at 5.5 A to about 8.5 at $13 \mathrm{~A}$, limited decrease is noted at higher currents, this could be due to the higher rates of electrode consumption.

\subsubsection{Effect of current on white layer thickness (WLT)}

Current effect on WLT is shown in Figure 4, while microphotographs in Figure 5 shows increased WLT resulting from discharge current of 19.5A.

Higher current means greater discharge energy thus more extensive effect of melting and re-solidification, therefore greater depth of re-solidified layer. Increasing the current causes a corresponding increase in the WLT. This is because during the subsequent cooling the molten material re-solidifies to form the "recast layer" the depth of which depends upon the volume of the molten material which was left on the surface immediately after the discharge process. On the other hand, Figure 6 shows the effect of high current in damaging the white layer, which also shows that the white layer is non-homogenous and discontinuous. This agrees with previous researchers' findings $[4,5]$. 


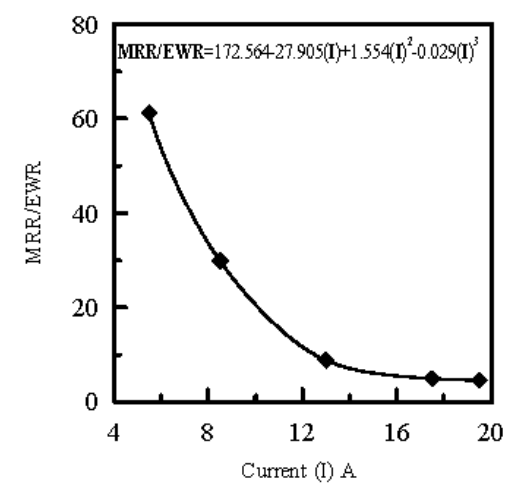

Figure 3: Variation of (MRR/EWR) ratio with discharge current of EDM steel DIN 1.2714 specimens, $\mathrm{V}=$ $85 \mathrm{~V}, \mathrm{~T}_{\text {on }}=\mathrm{T}_{\text {off }}=50 \mu \mathrm{s}$.

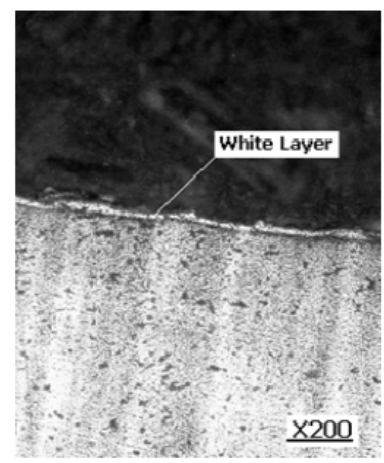

(a)

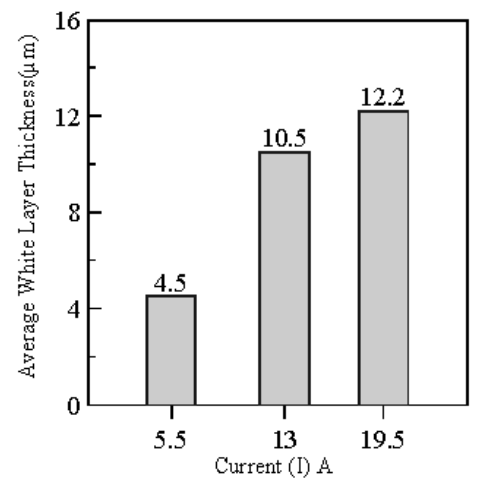

Figure 4: Variation of WLT with discharge current of EDM steel DIN 1.2714, $\mathrm{V}=\quad 85 \mathrm{~V}, \quad \mathrm{~T}_{\text {on }}=\mathrm{T}_{\text {off }}=$ $50 \mu \mathrm{s}$.

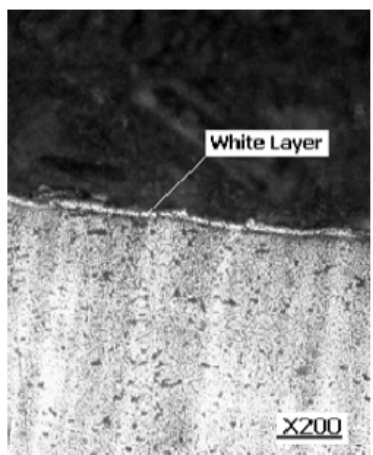

(b)

Figure 5: Optical microphotograph showing white layer of DIN 1.2714 steel specimen. (a) $\mathrm{I}=5.5 \mathrm{~A}$, (b) $\mathrm{I}=19.5 \mathrm{~A}$.

\subsubsection{Effect of pulse duration on average surface roughness (Ra)}

The effect of pulse duration on average surface roughness of EDM steel surfaces is exhibited in Figure 7. It can be seen that average surface roughness increases upon increase of pulse duration and that is due to temperature increase in the EDM zone, which causes extensive metal melting, this is believed to be the main reason behind surface roughness increase. It can be seen that surface roughness increases slightly when pulse duration increases from 25 to $50(\mu \mathrm{s})$. However the increase in surface roughness becomes more significant when pulse duration is in the range 50 to $100(\mu \mathrm{s})$. 


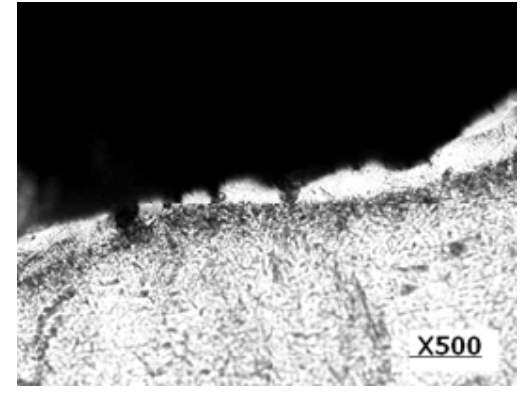

Figure 6: Optical microphotograph showing non homogeneity and discontinuity of the white layer in DIN 1.2714 steel specimen at $19.5 \mathrm{~A}$.

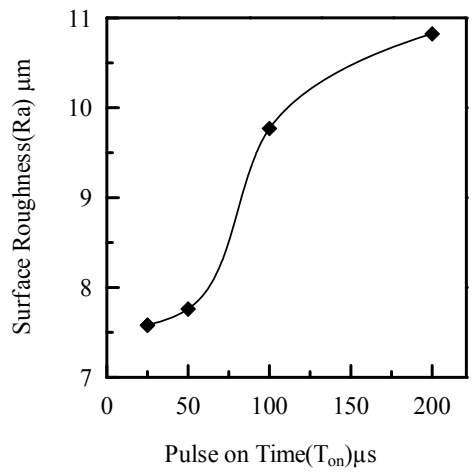

Figure 7: Variation of surface roughness with pulse on time of EDM steel DIN 1.2714 specimens, $\mathrm{V}=$ $85 \mathrm{~V}, \mathrm{I}=13 \mathrm{~A}$, Toff $=$ $50 \mu \mathrm{s}$.

\subsubsection{Effect of pulse duration on white layer thickness (WLT)}

Figure 8, shows the effect of pulse duration on the white layer thickness. As it may be noticed that the white layer thickness increases with pulse duration increase. However, it may be noted that white layer thickness increased by about $54 \%$ upon increasing pulse duration from 25 to $100(\mu \mathrm{s})$.

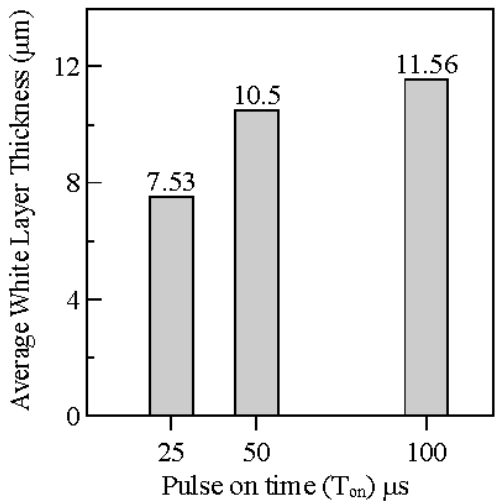

Figure 8: Variation of WLT with pulse on time of EDM steel DIN 1.2714 specimens, $\mathrm{V}=$ $85 \mathrm{~V}, \mathrm{I}=13 \mathrm{~A}, \mathrm{~T}_{\text {off }}=50 \mu \mathrm{s}$.

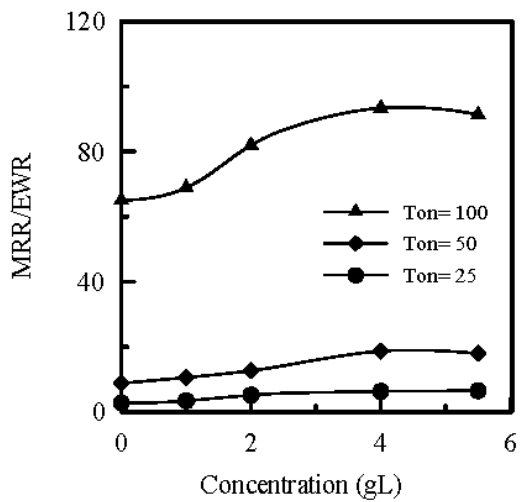

Figure 9: Variation of (MRR/ EWR) ratio with pulse on time and powder concentration of steel DIN 1.2714, I=13A, V= $85 \mathrm{~V}, \mathrm{~T}_{\mathrm{off}}=50 \mu \mathrm{s}$. 


\subsection{Graphite powder addition effect on EDM of steel DIN 1.2714}

\subsubsection{Effect on the ratio (MRR/EWR)}

The effect of graphite powder addition on the ratio (MRR/EWR) is demonstrated in Figure 9, where it can be seen that adding the graphite power has resulted in improving the ratio (MRR/EWR) which means economizing the EDM process. Statistical data analysis using the T-test showed that there is no significant difference in the ratio (MRR/EWR) due to 25 and $50(\mu \mathrm{s})$ pulse on time. However, EDM at $100(\mu \mathrm{s})$ pulse on time has resulted in a significant difference in the ratio (MRR/EWR), and this is attributed mainly to the significant drop in EWR.

It is worth emphasizing that reduced electrode consumption due to powder addition reached $65 \%$ as compared to electrode consumption when EDM without powder addition. It is also noted that the increase in the ratio (MRR/EWR) continues as the powder concentration increases from $1(\mathrm{~g} / \mathrm{l})$ to $4(\mathrm{~g} / \mathrm{l})$ then it shows slight drop at greater concentration. Statistical analysis using two-factor ANOVA with interaction was applied to steel DIN 1.2714 data to determine the effect of pulse on time, powder concentration and their interaction on the ratio (MRR/EWR),. The analysis revealed that the effect of pulse duration, powder concentration and interaction are significant. In addition, the contribution of pulse on time $(5 \%)$ was greater than that due to graphite powder contribution $(0.33 \%)$ in improving MRR; however, the greatest improvement $(74 \%)$ was attributed to current effect.

\subsubsection{Effect of graphite powder addition on the average surface roughness}

It is known generally that the presence of powder helps to increase the gap size and promotes the bridging effect, This lowers insulation of the dielectric and consequently helps in producing multiple discharging effect with a single input pulse (single pulse could generate several discharging spots on the surface) during the machining process. Fine debris formed in this way can be easily pushed away, thus resulting in lower surface roughness. The influence of graphite powder addition on average surface roughness is presented in Figure 10, showing limited variation of average surface roughness. It is also noted that average surface roughness decreases upon the use of powder when EDM is performed at pulse duration of $25(\mu \mathrm{s})$ while remains approximately unaltered with $50(\mu \mathrm{s})$, but it exhibits a slight increase in average surface roughness when graphite powder concentration is $5.5(\mathrm{~g} / \mathrm{l})$. However when EDM is performed at $100(\mu \mathrm{s})$ the surface roughness $\mathrm{Ra}$ decreases at $1(\mathrm{~g} / \mathrm{l})$ concentration, then it remains almost constant upon further increase of the powder concentration 2, 4, $5.5(\mathrm{~g} / \mathrm{l})$. Statistical T-test results indicated that surface roughness due to EDM at $50(\mu \mathrm{s})$ as compared to $100(\mu \mathrm{s})$ as well as results due to EDM at $25(\mu \mathrm{s})$ as compared to $100(\mu \mathrm{s})$ were found to be significantly different at $5 \%$ level. Accordingly, it may be suggested that if surface roughness is to be maintained at its minimum level then $4(\mathrm{~g} / \mathrm{l})$ powder concentration seems to be the most appropriate regarding the steel DIN 1.2714 under the EDM machining conditions considered. Present results are found to be agreeable with previous researchers regarding the effect of powder concentration on average surface roughness $[8,9]$. 


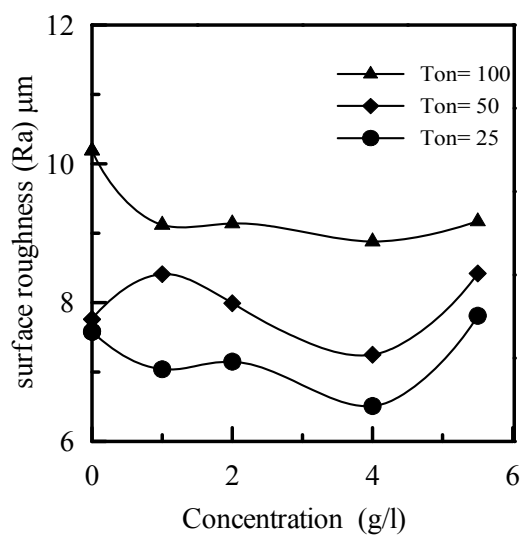

Figure 10: Variation of surface roughness with pulse on time and powder concentration of steel DIN $1.2714, \mathrm{I}=13 \mathrm{~A}, \mathrm{~V}=85 \mathrm{~V}$, Toff $=50 \mu \mathrm{s}$.

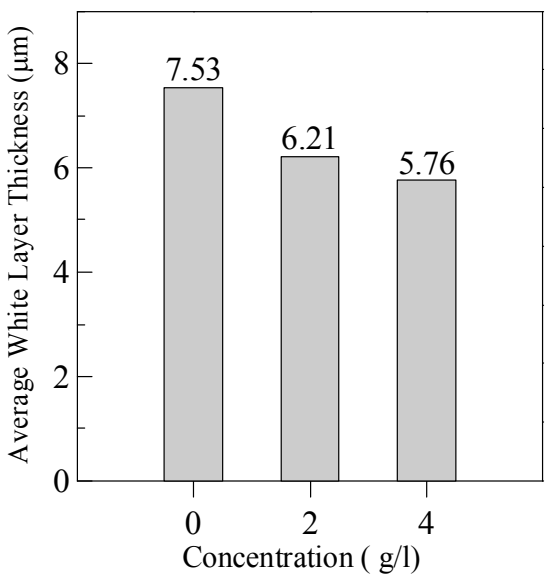

Figure 11: Variation of WLT due to PMEDM of steel DIN $1.2714 \mathrm{I}=13 \mathrm{~A}, \mathrm{~V}=85 \mathrm{~V}$, Ton $=25 \mu \mathrm{s}$, Toff $=50 \mu \mathrm{s}$.

\subsubsection{Effect of graphite powder addition on white layer thickness (WLT) and homogeneity}

It is known that increasing pulse duration and current both causes increase of white layer thickness, it is to be expected that WLT will be reduced upon the use of powder during EDM process. Due to the role of powder particle to generate several discharging spots on the machined surface. The addition of powder was reported [7] to reduce the abnormal discharge rate by more than $40 \%$. Thus it is expected that graphite powder suspension will produce more uniform discharges. Figure 11, exhibits the effect of graphite powder at various concentrations on the white layer thickness. The influence of powder addition on white layer thickness and homogeneity is shown in Figure 12, where it can be seen that graphite powder addition has resulted in reduction of the WLT. In that regard examination of the WLT was carried out on limited steel specimens subjected to EDM with powder concentration of 2 and $4(\mathrm{~g} / \mathrm{l})$, results showed thinner and more homogenous recast layer at higher powder concentration $4(\mathrm{~g} / \mathrm{l})$. This is due to more uniform sparking and less abnormal discharges with powder addition.

Moreover, the presence of powder results in increasing the sparking spots, and therefore improving the hardening effect.

\subsection{Graphite powder addition effect on EDM of steel DIN 1.2343}

\subsubsection{Effect of graphite powder addition on the ratio (MRR/EWR)}

The effect of graphite powder at various concentrations on the ratio (MRR/EWR is shown in Figure 13, as it is noted that there is a slight increase in the ratio 


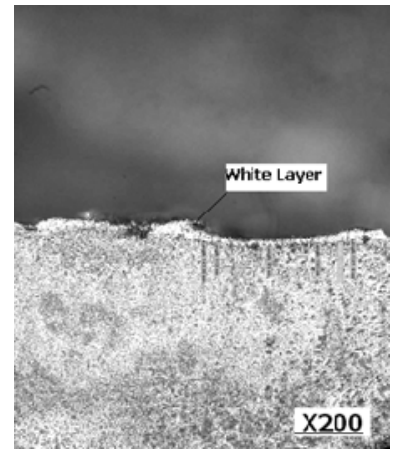

(a)

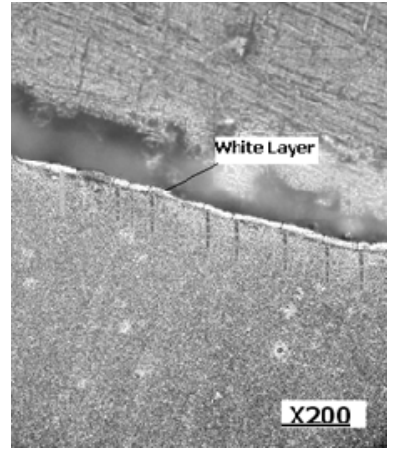

(b)

Figure 12: Microphotograph showing white layer of DIN1.2714 steel: (a) $0(\mathrm{~g} / \mathrm{l})$; (b) $4(\mathrm{~g} / \mathrm{l})$.

when using pulse on time 25 and $50(\mu \mathrm{s})$ which is found to be insignificant upon statistical analysis using T-test, whereas the increase of the ratio was found significant when pulse on time was $100(\mu \mathrm{s})$. It can be noted that the ratio $(\mathrm{MRR} / \mathrm{EWR})$ is at its highest level when powder concentration is $2(\mathrm{~g} / \mathrm{l})$. This may be reasoned as follows, carbon nuclide attached on the electrode surface might be responsible for reduced EWR on the other hand, higher powder concentration leads to increased gap size and perhaps decrease mechanical thrust resulting from gas explosion upon working fluid evaporation. In effect weaker gas explosion in the interspace could have led to a reduction in MRR during EDM process.

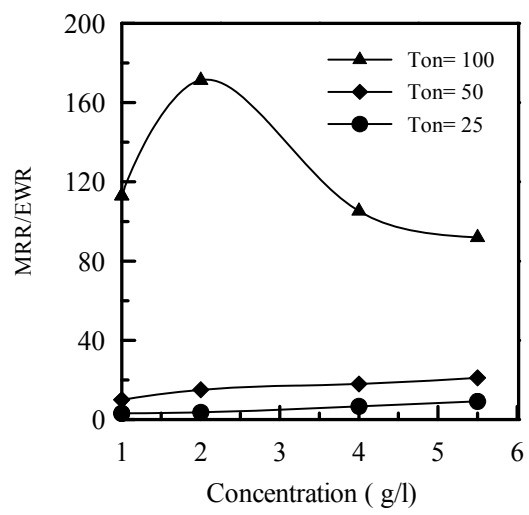

Figure 13: Variation of (MRR/ EWR) ratio with pulse on time and powder concentration of steel DIN 1.2343, I=13A, V= $85 \mathrm{~V}, \mathrm{~T}_{\text {off }}=50 \mu \mathrm{s}$.

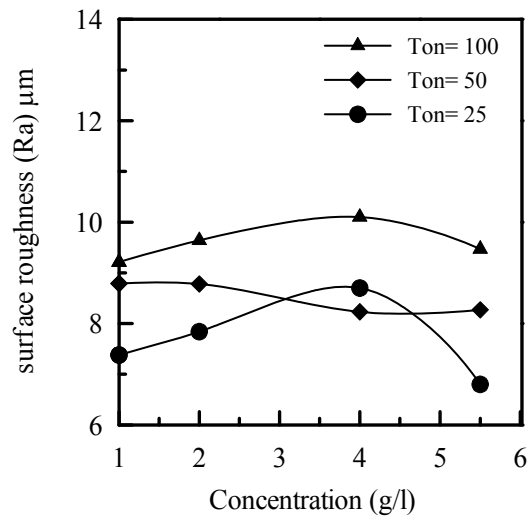

Figure 14: Variation of surface roughness with pulse on time and powder concentration of steel DIN 1.2343, I=13A, V= $85 \mathrm{~V}, \mathrm{~T}_{\mathrm{off}}=50 \mu \mathrm{s}$. 
Statistical analysis using Two- Factor ANOVA with Interaction, applied to the obtained data due to EDM of steel DIN1.2343, showed that there is a significant effect of the pulse duration on the ratio (MRR/EWR) however no significant effect is found due to powder concentration or their interaction at $5 \%$ level of significance meanwhile at $10 \%$ level the interaction effect becomes significant. On the other hand two factor ANOVA test results considering the effect of steel type, pulse duration and their interaction on the ratio (MRR/EWR), it is found that there is no significant difference at 5\% level of significance; however pulse duration effect became significantly different at $10 \%$ level of significance.

\subsubsection{Effect of graphite powder addition on the average surface roughness}

The influence of graphite powder addition at different concentrations on the $\mathrm{Ra}$ is presented in Figure 14, and it is noted that Ra due to EDM at $25(\mu \mathrm{s})$ increases to over about $9(\mu \mathrm{m})$ at powder concentration of $4(\mathrm{~g} / \mathrm{l})$ then average surface roughness drops when powder concentration reaches $5.5(\mathrm{~g} / \mathrm{l})$. Meanwhile, when EDM is performed at $50(\mu \mathrm{s})$ pulse on time, mild gradual decrease of the average surface roughness was observed as concentration increased to $4(\mathrm{~g} / \mathrm{l})$ then remained unaltered. As for $100(\mu \mathrm{s}) \mathrm{Ra}$ showed its highest value over $10(\mu \mathrm{m})$ when powder concentration is $4(\mathrm{~g} / \mathrm{l})$ then a slight decrease upon powder concentration increase to $5.5(\mathrm{~g} / \mathrm{l})$. Statistical T-test results indicated that there is no significant difference between surface roughness due to 25 and $50(\mu \mathrm{s})$ pulse duration., However, surface roughness due to EDM at 50 as compared to 100( $\mu \mathrm{s})$ as well as results due to EDM at 25 as compared to $100(\mu \mathrm{s})$ were found to be significant at $5 \%$ level.

Since EDM of this steel DIN1.2343 was carried out only with powder addition, thus direct comparison with surface roughness results due to EDM of the same steel without powder addition is not possible, however it may speculated based on present finding on steel DIN1.2714 and previous researchers findings $[8,9]$ that average surface roughness $\mathrm{Ra}$ is expected to decrease upon EDM with powder addition. Furthermore, previous research [13] results showed limited contribution of powder effect on $\mathrm{Ra}$, this comes in agreement with the present results Figure 14, which shows limited variation of surface roughness \pm 1 $(\mu \mathrm{m})$ with powder concentration for all pulse duration applied.

\subsubsection{Effect of graphite powder addition on white layer thickness (WLT) and homogeneity}

The effect of graphite powder at various concentrations on the white layer thickness is shown Figure 15; it is also evident that increasing powder concentration causes a decrease in the WLT. It may also be noted that as powder concentration increases from 2 to 4 (g/l) WLT decreases and becomes more homogeneous. Considering both steels, it is found that the effect of powder concentration on white layer thickness decreases by $13 \%$ for DIN 1.2343 as compared to $7 \%$ for DIN 1.2714 upon concentration increase from 2 to 4 (g/l). 


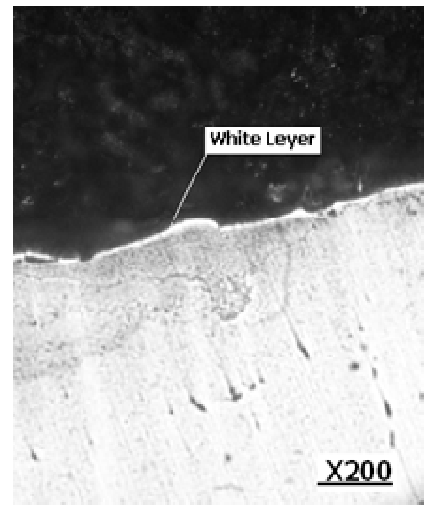

(a)

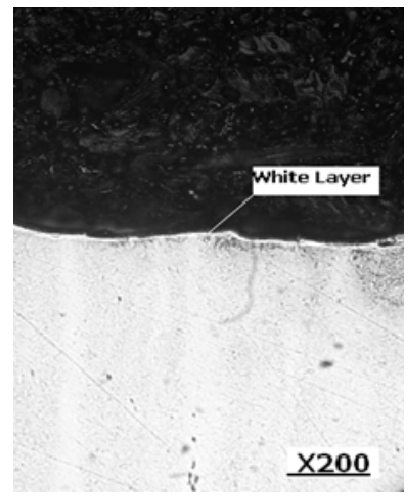

(b)

Figure 15: Optical microphotograph showing white layer of DIN 1.2343 steel specimen: (a) 2(g/l); (b) 4 (g/l).

\section{Conclusions}

1) Regarding the type of steel and pulse duration two factor ANOVA test showed no significant difference in their effect on the ratio MRR /EWR at 5\%; however, at $10 \%$ level of significance, pulse duration effect became significant.

2) Graphite powder addition caused reduction in electrode consumption thus signifying the economical importance of using graphite powder.

3) Graphite powder addition produced slight reduction in surface roughness. Nonetheless, the present results suggests that $4(\mathrm{~g} / \mathrm{l})$ and $5.5(\mathrm{~g} / \mathrm{l})$ are the best.

4) White layer thickness reduction in steel DIN 1.2343 was greater than that in steel DIN 1.2714 when powder concentration is increased from 2 to $4(\mathrm{~g} / \mathrm{l})$.

\section{References}

[1] Kozak J. \& Rajurkar K., Hybrid Machining Process Evaluation and Development. http://www.unl.edu/nmrc.

[2] Shanker S., Maheshwari S. \& Pandey P.C., Some investigations into the electric discharge machining of hardened tool steel using different electrode materials. Journal of Materials Processing Technology, Vol. 149, pp. 272-277, 2004.

[3] Davis J. R., Machining. ASM Handbook, Vol. 16, 1989.

[4] Guu Y.H., Hocheng H., Chou C.Y. \& Deng C.S., Effect of electrical discharge machining on surface characteristics and machining damage of AISI D2 tool steel. Journal of Materials Science and Engineering A358, pp. 37-43, 2003. 
[5] Lee H.T. \& Tai T.Y., Relationship between EDM parameters and surface crack formation". Journal of Materials Processing Technology Vol. 142, pp. 676-683, 2003.

[6] Kansal H. K., Sehijpal S. \& Kumar P., Parametric optimization of powder mixed electrical discharge machining by response surface methodology. Journal of Materials Processing Technology Vol. 169, pp. 427-436, 2005.

[7] Pecas P. \& Henriques E., Influence of silicon powder-mixed dielectric on conventional electrical discharge machining. International Journal of Machine Tools \& Manufacture Vol. 43, pp. 1465-1471, 2003.

[8] Tzeng Y. F. \& Chen F. C., Investigation into some surface characteristics of electrical discharge machined SKD-11 using powder-suspension dielectric oil. Journal of Materials Processing Technology (170), pp. 385$391,2005$.

[9] Uno Y., Okada A. \& Cetin S., Surface Modification of EDMed surface with powder mixed fluid. Proc. Of the $2^{\text {nd }}$ Int. Conf. on Design and Production of Dies and Molds, 2001.

[10] Zhao W.S, Meng Q. G. \& Wang Z.L., The application of research on powder mixed EDM in rough machining. Journal of Materials Processing Technology, Vol. 129, pp. 30-33, 2002.

[11] Tzeng Y.-F\& Lee C.Y., Effects of powder characteristics on electro discharge machining efficiency. Int. Journal of Advanced Manufacturing Technology, Vol. 17, pp. 586-592, 2001.

[12] Electro Discharge Machining, http://www.edmtt.com/articlesreports /index.htm.

[13] Kansal H.K., Sehijpal S. \& Kumarc P., A study on the machining parameters optimization of powder mixed electrical discharge machining (PMEDM) Int. Con. On Production Engineering Design and Control (PEDAC), Alexandria, 2004.

[14] Wang J. Han F., Cheng G. \& Zhao F., Debris and bubble movements during electrical discharge machining. Int. Journal of Machine Tools and Manufacture, Vol. 58, pp. 1-54, 2012.

[15] Shabgarda M.R. \& Seyedzavvara, R.A.M., Mathematical and numerical modeling of the effect of input-parameters on the flushing efficiency of plasma channel in EDM process. Int. Journal of Machine Tools and Manufacture, Vol. 65, pp. 79-87, 2013. 